\title{
IoT-oriented software platform applied to sensors-based farming facility with smartphone farmer app
}

\author{
P. Visconti ${ }^{1}$, N. I. Giannoccaro ${ }^{2}$, R. de Fazio $^{3}$, S. Strazzella ${ }^{4}$, D. Cafagna ${ }^{5}$ \\ ${ }^{1,2,3,5}$ Department of Innovation Engineering, University of Salento, Italy \\ ${ }^{4}$ Asepa Energy Company, Italy
}

\section{Article Info \\ Article history: \\ Received Oct 31, 2019 \\ Revised Jan 9, 2020 \\ Accepted Feb 19, 2020}

\section{Keywords:}

Cloud software platform

Data processing

IoT devices

Precise Farming

Solar-powered sensornode

Wireless sensor network

\begin{abstract}
This work describes the design of innovative IoT-oriented farm management system that employs low-cost WSN for detecting soil, environmental and crops parameters that properly processed, in combination with weather forecasts, are used to determine future farming activities based on agronomic models implemented in the software platform. Goals of carried out research activity are to guarantee production both qualitatively and quantitatively of cultivated crops, to increase company income and reduce environmental impacts; achieving these objectives is a prerequisite for implementing of sustainable agriculture. Connection between traditional cropping systems and innovative technologies is achieved through the utilization of low-cost wireless electronic modules for acquiring data from connected sensors. The fertigation system operation is supported by solar-powered low-cost WSN capable of constantly monitoring soil and environmental parameters; thanks to sensor nodes properly positioned in cultivated land or greenhouse, interest parameters of both air and soil are detected and transmitted to on-cloud database, to allow monitoring and remote control from enabled users (farmer or agronomist). For this aim, an application specifically realized and tested during the different fertigation system's functional tests, allows users to visualize and eventually remotely intervene by using a smart-phone or tablet.
\end{abstract}

This is an open access article under the CC BY-SA license.

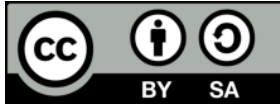

\section{Corresponding Author:}

P. Visconti,

Department of Innovation Engineering, University of Salento,

Road to Monteroni, Ecotekne Campus, Lecce, 73100, Italy.

Email: paolo.visconti@unisalento.it

\section{INTRODUCTION}

The synergy between sectors belonging to different fields such as electronic engineering, robotics, information technology, agronomy, agricultural mechanics and telecommunications represents the trend of the agriculture sector in which the development of sustainable agriculture is possible [1]. A recent common aim of Industry 4.0 is to find a solution that integrates the modern technologies with the agricultural sector's needs, taking into account low environmental impact by means of the renewable energy sources. In order to address the challenges of smart and sustainable farming, the complex agricultural eco-systems need to be better analysed; nowadays, the digital technologies can contribute to improve the sustainable agriculture and help the farmer, thanks to the provided possibility to monitor and measure continuously various quantities related to environment and soil as well as to crops growth, thus producing large quantities of data in an unprecedented pace [2]. The analysis of these data, by the IoT technologies, will enable farmers and companies to extract value from them, thereby improving their productivity. Besides the numerous application fields in which Wireless Sensor Networks (WSN) can be employed, their usage in agriculture 
is growing faster in the last few years: smart and precision farming are emerging terms used to indicate integrated systems with high specialization levels designed for agricultural automation based on low-cost wireless communication modules and remote control technologies [3-6]. The automation, increasingly widespread thanks to the rapid and growing technological development, is nowadays already present in all the realities of the agricultural sector, for instance in ag ricultural greenhouses where conditioning and control systems of the environmental as well as cultivated land parameters are implemented through appropriate sensors and actuation modules. Therefore, it has become indispensable to equip also outdoor agricultural structures with control systems including electric panels, electronic equipment dedicated to specific tasks, for example, to detect environmental or crops' parameters such as humidity, luminosity, $\mathrm{CO}_{2}$ concentration, etc.

The developed IoT-oriented system is a solar-powered smart fertigation platform integrated with a low-cost WSN for monitoring directly on-field cultivated crops and thus supporting farmers in the decision-making phases related to agricultural processes through the agronomic models implemented in the software platform. The aim is to obtain a rational use of fertilizers and water resources according to the real crops' nutritional needs and consequently an environmental impact reduction; to achieve this purpose, fertigation scheduling is planned based on crops interest parameters, detected by developed solar-powered WSN, and on weather forecast. An advantage of such approach regards its easy scalability, so improving performances of an existing WSN-based application; for instance, additional sensor nodes can be easily added to existing architecture for monitoring more crops' or land parameters as well as spread of pests or diseases [7, 8]. Moreover, an IoT-based communication system has been employed in order to periodically transfer WSN data on cloud to be stored, whereas a smart-phone app is available to user for visualizing and controlling WSN operation, getting crops growth parameters, for consulting the agronomic models or database and finally for driving locally the fertigator operation $[8,9]$.

The developed software platform acquires sensors data and weather forecasts continuously and use s them in mathematical agronomic models to support farmers in the decision-making processes related to necessary treatments for growth and development of crops. The DSS implemented in the software platform uses always updated databases on fertilizers and plant protection products, which include all the technical features that allow the selection of the most suitable products for each specific application, also in relation to anti-resistance strategies, thus becoming an effective tool for adapting cultural techniques to climate changes. Moreover, the carried out research work aimed to obtain the traceability of the agricultural products ensuring the information storage on the treatments undergone by the products during the cultivation phases, allowing data viewing remotely on smartphone/tablet; also, by using a multi-platform Web-App, the agronomist or farmer can identify, by reading a QR-code, a specific section of cultivated land and view/update the related information or finally require details about the performing of a specific treatment on the cultivated crops. The manuscript is organized as follows: the second paragraph includes a literature analysis on agronomic models and decision support systems (DSSs) more widespread in optimized management systems in the agricultural sector. In the next paragraph, a detailed description of the hardware sections and functionalities of designed WSN and solar-powered fertigation system is reported; after the developed software platform for the fertigator remote control and app's functionalities available for the farmer or other users are described in detail, to finally conclude with the conclusions.

\section{LITERATURE ANALYSIS ON AGRONOMIC MODELS AND DECISION MAKING ALGORITHMS IN PRECISION FARMING}

Decision-making processes have become much more complex and the knowledge and problems that the agricultural company has to face are increased. The DSSs are the best tool to provide all the needed and updated information for the management of a specific crop, disease or infestation [10]. Furthermore, a key task of the fertigation apparatus presented here is to provide highly qualified services relatively to the crop production and to increase the competitiveness of agricultural enterprises through the development of a DSS for the sustainable management of crops based on new information technologies, the transfer of technological innovation in the sectors of intensive and extensive agricultural crops, with particular reference to productivity, environmental sustainability and food security. Typically, a DSS consists of two main parts: An integrated system for the real-time monitoring of interest parameters related to the cultivated products and the memorization of related data; whereas, the second part consists of an application available on-line which, analyzing these data with advanced modeling techniques, provides real-time alerts and information for supporting the decision-making process as shown in Figure 1. Then common users or farmers use these informations for agronomic precision crop management; data on cultivation operations also enter in the on-cloud databases, in order to generate a continuous flow of updated information between the crop, DSS, and the farmers [10, 11]. 
An example of DSS to be cited is vite.net based on a network of weather stations, a server repository able to store weather data and site-specific information on cultural management (such as the list of treatments applied), a set of mathematical models, that use the real-time data collected in fields as input data to produce useful information, by the developed DSS, about the tactical management of treatments and other cultural practices [12]. The DSS provides a sprouting time estimate, of leaves emission dynamics on the main shoots and of phenological development of the reproductive phases; in this way, it allows to plan irrigation and fertigation phases based on plants development and on soil water needs, so avoiding water stress of the crops.

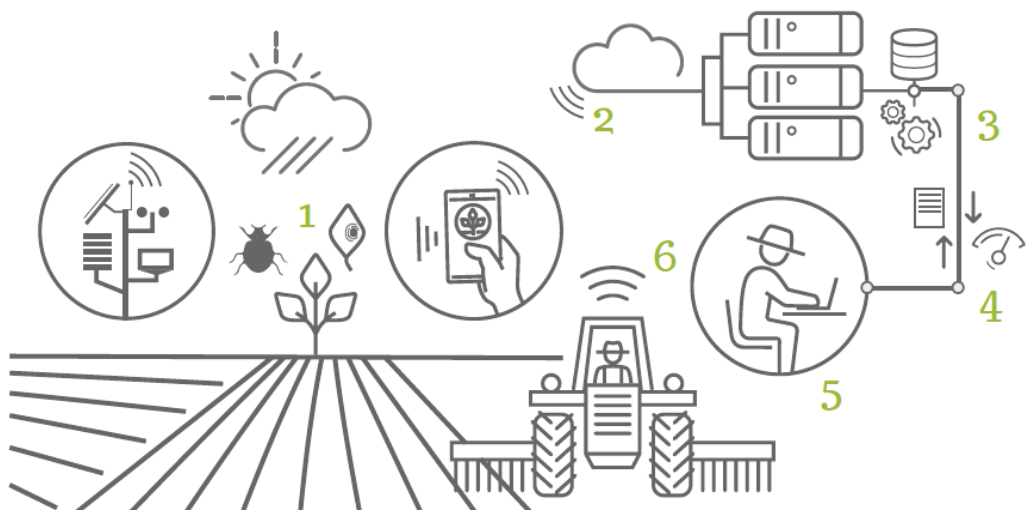

Figure 1. (1) DSSs are computer platforms that collect in real time cultivation data through sensors and scouting tools, (2) Organize these data in cloud systems, (3) Interpret them using advanced modeling and big data techniques and (4) Integrate them automatically, producing information, alarms and decision support; (5) Users use information for agronomic precision crop management; (6) Data on cultivation operations enter in databases in order to generate continuous flow of updated information between the crop, DSS, and farmer

Through forecasting models of infection, vite.net DSS allows controlling harmful organisms (eg downy mildew, black-rot, botrytis, grapevine moth, planococcus and scaphoid), evaluating the need for an intervention and choosing the most suitable plant protection products. Finally, DSS has the functionality to alert wine-growers of the potential risk related to cold or heat damage and by so-called cultivation register to record all the operations carried out in the vineyard up to the products delivery. In ref [13], the researchers developed a DSS that uses readily available data to farming facilities allowing use by multiple stakeholders and so the design of efficient and sustainable farms' networks to reduce their post-harvest losses. Carried out simulations showed that after 55 years, the market traders in an optimal network will incur a $21 \%$ cheaper total transportation cost than they would in the existing network [13]. A DSS developed to aid decision-making about olive harvesting machines is presented in [14]; authors defined the main effective criteria that play an imperative role in olive harvesting machines selection such as cost, vibration, efficiency, suitability, automation, work capacity, ergonomics and safety. They classified criteria in 3 groups assigning to them some weights (beneficial, non-beneficial and target-based criteria) and applying the target-based technique to normalize the decision matrix as well as the best-worst method for as signing weights to criteria [14].

Many research works are focused, besides to the development of increasingly performing DSS, also in the big data management in agro-environmental research. The large opportunities of big data analysis in agriculture towards a smarter farming are highlighted in [2]; in this research work, the authors show that the availability of hardware and software techniques and methods for big data analysis, as well as the increasing openness of big data sources, shall encourage more academic research, public initiatives and business ventures in the agricultural sector. Big data technologies, together with the increased use of cloud based and high performance computing, create new opportunities for data intensive science in the multi-disciplinary agro-environmental domain. In [15], a theoretical framework is proposed, which allows the positioning of big data challenges and techniques in the context of inter-disciplinary science and the policy-science interface; then, this framework is employed to analyze three scientific cases in the agro-environmental domain in order to evaluate on the current state of the application of big data technologies in this economic fields. The case studies analyzed by the authors indicate that most persistent issues in the area of data-intensive research evolve around capturing the huge heterogeneity of interdisciplinary data and around creating trust between data providers and data users [15]. 
With the emergence of IoT technology and devices, huge number of low cost and low power sensors nodes can easily be deployed in farmlands, in order to gather on crops and climate precise data and then to forward the collected data, by Internet connection, to the so called cloud IoT framework; in this cont ext, a new DSS based on sensors network specifically developed for potatoes late blight disease prevention is presented in [16]. An innovative approach for monitoring parameters related to the cultivated products in fields several kilometers in size is proposed in [17] for covering long distances in a short period of time, the authors use an unmanned aerial vehicle (UAV), which retrieves the data stored from the on -ground sensor nodes. The UAV may be used to acquire additional information; in fact, its elevated position allows an observation of the field with a perspective that is useful for detecting changes affecting crops, such as localized spread of pests, diseases, significant changes in soil moisture, drought or floods [17]. Agro-industrial and environmental applications that are using Internet of Things (IoT) are widely discussed in [18], where the current state of solutions in these fields (agro-industrial / environmental applications), as well as trends, architectures, technologies and open challenges are analyzed. Recently, the deep learning, a technique for image processing and data analysis, was introduced in agriculture domain; in [19], the authors perform a survey of 40 research efforts that employ deep learning techniques, applied to various agricultural and food production challenges, providing, for a particular agricultural case study, the models, the frameworks employed, the sources, the nature and the pre-processing of collected data.

\section{RESEARCH METHOD}

\subsection{Hardware sections and functionalities of designed WSN and solar-powered fertigation system}

The designed fertigation system is composed of several hardware sections. The hydraulic one, placed in a wooden cottage, includes electric pumps and collectors; it is also equipped with tanks for the fertilizers solutions and solenoid valves for controlling the proper irrigation of each area of the land. In the zoomed area of Figure 2(a), the components of the fertilizers' bin are shown: the dosing screw (A), the bin with the fertilizer in powder or liquid, the electric motor for actuating the screw (C). The fertilizer tank is a section of the hydraulic and electric system as shown in Figure 2(b) that also includes electric pump for distributing water (C), a water filtering system (D), the electric motor for actuating mixing helix (E), and the mixing helix (F).

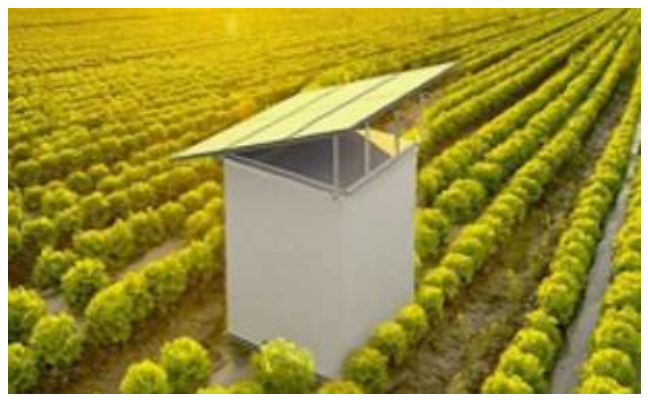

(a)

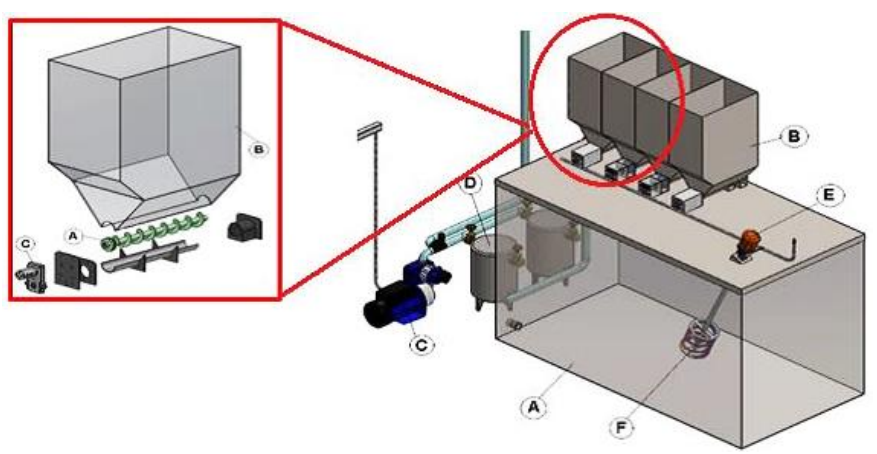

(b)

Figure 2. (a) Fertigation systemcottage, (b) Its components and the fertilizer bin in the zoomed image

A mechanical system with several bins (from 1 up to 5) allow precise dosing of each fertilizer inside the bin; in this way, the fertilizer solution can be properly optimized by using a remotely controlled screw conveyor for each fertilizer. Also, if a greenhouse is managed, it is needed a conditioner module in order to establish correct climate conditions for the cultivated products; therefore, the integration with a low enthalpy horizontal geothermal system with a biomass boiler (e.g. using wood chips) needs to be realized. In addition, by controlling the conditioning system to optimize humidity and temperature values, the phenological maturation of the cultivated products can be affected and optimized in order to delay or anticipate their collection, allowing the farmer to schedule the harvest time according to requests of buyers notified through the software application. In Figure 3(a), a schematic representation is reported with indicated the paths of data gathered by means of WSN; they are stored in the database relative to the specific crop and compared with threshold values for regulating system operation. After, the data are sent by an internet connection to a remote server and stored in the cloud database to which common users, farmers and stakeholders access for 
viewing crops parameters and scheduled fertigation programs. The cloud platform periodically updates the farming management system by using WSN data and those provided by weather service, for evaluating, according to the answers provided by the agronomic models, any change of parameters thresholds relating to the programmed agricultural processes; in this way, irrigations number and time duration, beside the amount and typology of fertilizers, are optimized. In addition, the common user or farmer, by mobile device and internet connection, can assess the system state and access to all information (such as agronomic and WSN data, crops growth details) as well as he can control the planned actions or actuate autonomously other ones. The WSN architecture considered more suitable is the tree one, featured by the division of cultivated land in clusters with inside several sensor nodes that placed in different positions gather information from sensors; one coordinator node for cluster as shown in Figure 3(b) collects data from sensor nodes belonging to cluster and retransmits wirelessly them to the control unit and then towards the cloud software platform. The sensor node core is ESP8266 NodeMCU module equipped with microcontroller and wireless connectivity, shown in Figure 4; small dimension, low power consumption, Wi-Fi networking capabilities, GPIOs availability for connecting external sensors and other devices directly to embedded processor and high computation speed of Esp8266 chip make the prototyping board versatile allowing an easy integration in different fields (home automation, wearable agronomic and industrial applications), with the capability of remote control through Internet [20].

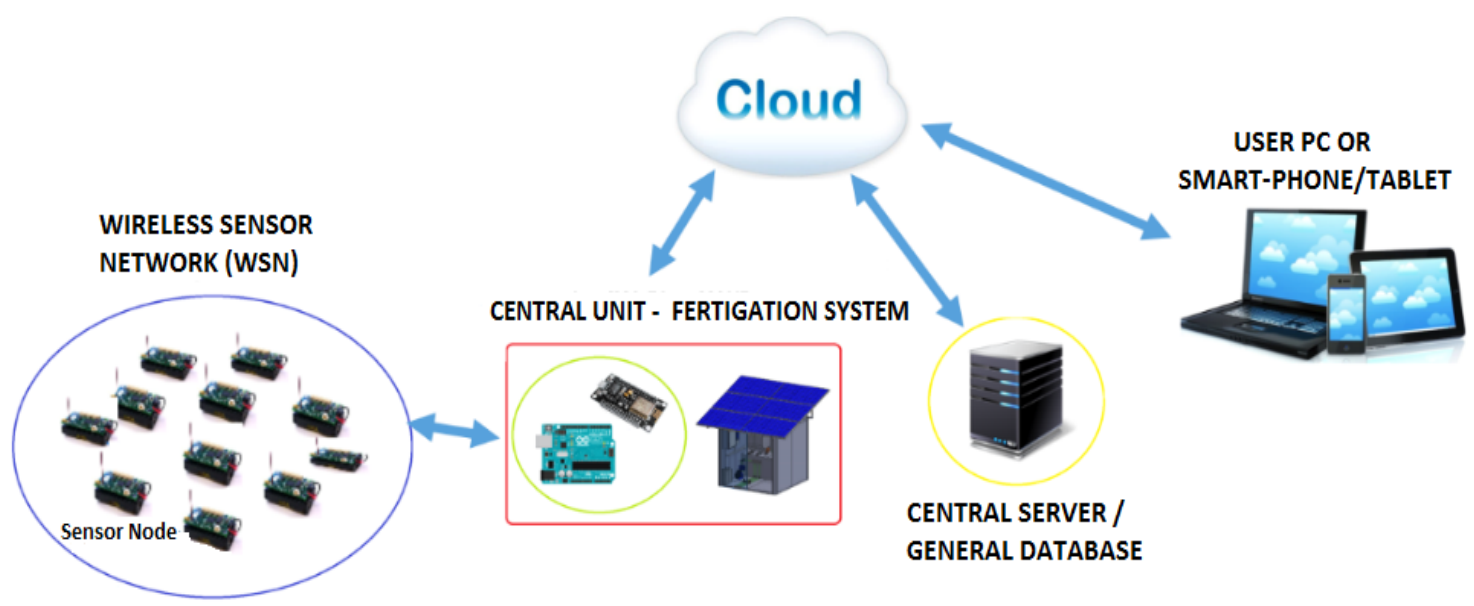

(a)

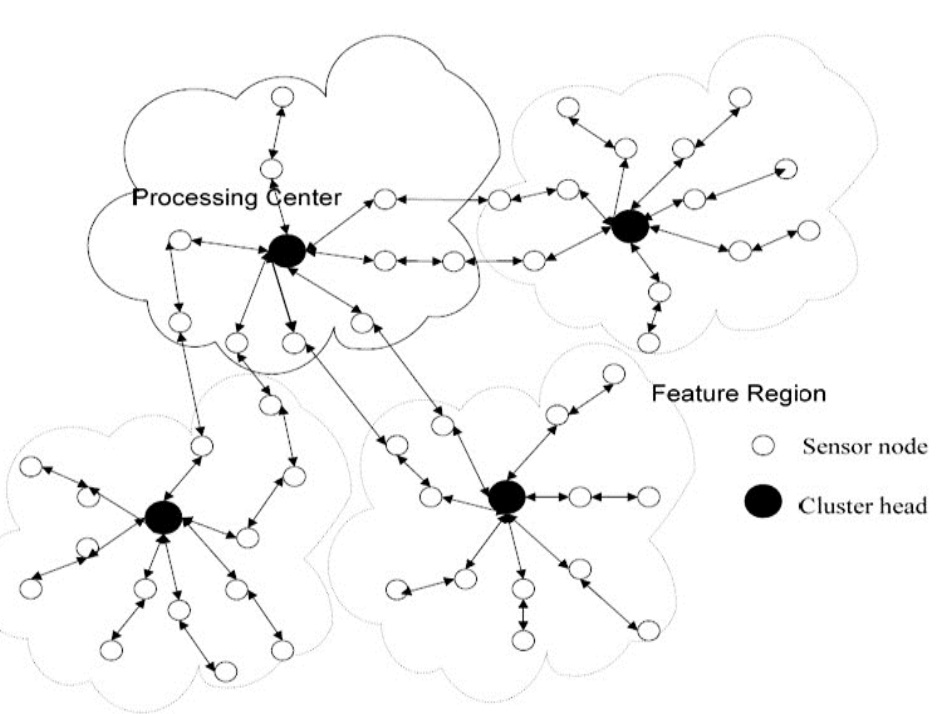

(b)

Figure 3. (a) Functional scheme of the entire system connected to the on-cloud platform, highlighting the data paths between the hardware components, (b) Representation of realized WSN with tree topology 
For measuring environmental humidity and temperature, a DHT22 1-Wire sensor was used (Figure 4, Sensing Unit box) with power supply voltage in the range 3.3-6 V, temperature measurement range from $-40^{\circ} \mathrm{C}$ to $+80^{\circ} \mathrm{C}$ and accuracy $\pm 0.5^{\circ} \mathrm{C}$, whereas for humidity, range $0 \%-100 \%$ and accuracy $\pm 2 \%$. For detecting soil moisture, the analog SEN0193 capacitive sensor was used (Figure 4, Sensing Unit box); thanks to the anti-corrosive layer that covers the sensing electrodes, it is able to withstand prolonged contact with the ground [21]. It has a power supply range from $3.3 \mathrm{~V}$ to $5 \mathrm{~V}$ and operating current of $5 \mathrm{~mA}$, providing an output voltage between 0 to $3.3 \mathrm{~V}$ proportional to soil moisture. Also sensor node is equipped with water-proof probe based on SHT11 digital sensor produced by Sensirion (Figure 4, Sensing Unit box) for measuring soil moisture and temperature; it is featured by a supply range 2.4-5.5 $\mathrm{V}$, temperature and moisture ranges $-40-123^{\circ} \mathrm{C}$ and $0 \%-100 \%$ respectively (with accuracy $\pm 0.5^{\circ} \mathrm{C}$ at $25^{\circ} \mathrm{C}$ and $\pm 3.5 \%$ ) [22]. SHT11 sensor is equipped with 14bit ADC for converting physical quantities to be provided by two wire $\mathrm{I}^{2} \mathrm{C}$ interface to input pin of ESP8266 NodeMCU board. In the Power Unit box of Figure 4, a schematic view of the power supply section is shown with $1.5 \mathrm{~W}$ amorphous silicon solar panel connected to the LTC3105 step-up converter for charging super-capacitor or lithium battery properly dimensioned for getting node long energy autonomy (up to 6-8 days in case of total absence of solar radiation, depending on nodes querying frequency). Because the most relevant node power consumption is due to data transmission phase, suitable strategy was implemented in the firmware; the sensor node acquires interest parameters, sends them to the relative coordinator node and goes in deep sleep mode for $30 \mathrm{~min}$ for restarting operation cycle after such time. Conversely, if transmission towards the coordinator node fails, the node retries this operation after 2 min until connection is got. The cluster coordinator node collects data from sensor nodes for $30 \mathrm{~min}$ and then sends data packet to the control unit, to then return to the listening phase. Described operation requires an agreement between transmission times of different nodes for avoiding collision between the transmissions towards the same coordinator node; this is obtained by properly scheduling the transmission times of nodes for avoiding overlapping [23, 24].

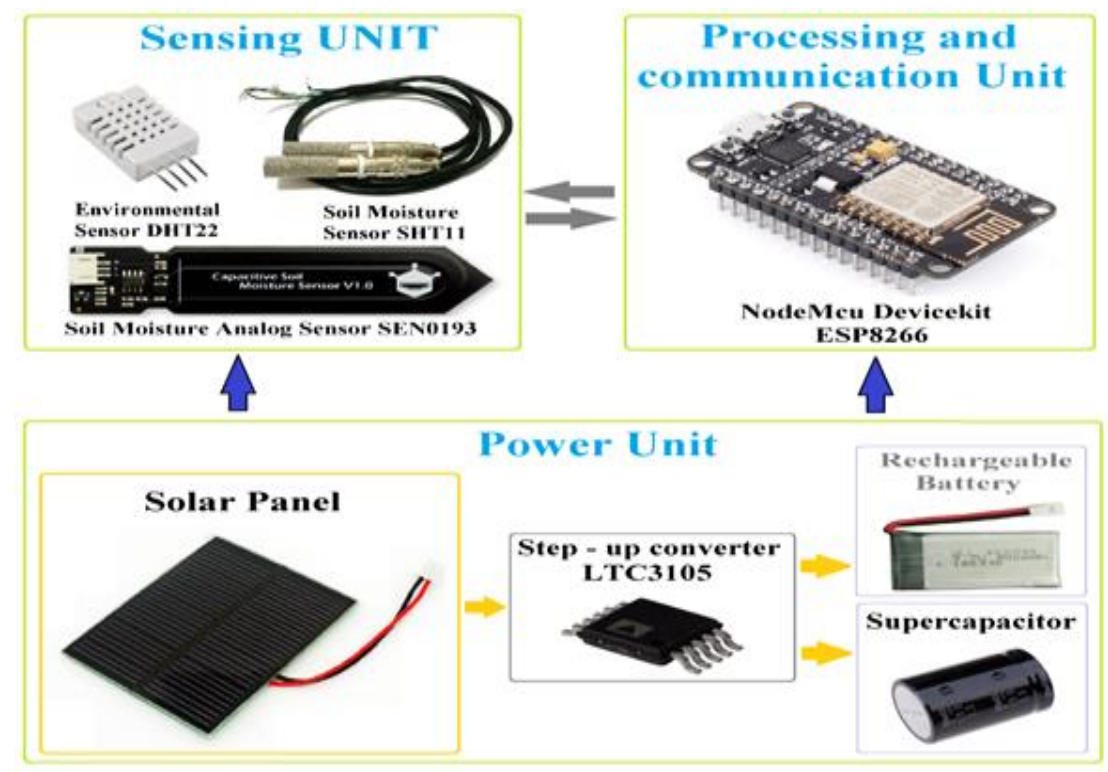

Figure 4. Sensor node block diagram able to detect and transmit soil and environment parameters wirelessly

The coordinator node has the function to generate the local network to which sensor nodes have to connect and to gather data from WSN nodes within prefixed time interval, sending then them to the control unit installed in the central body of farming facility, according the flowchart modalities of Figure 5(a) [23]. It was designed by using NodeMCU module with a proper firmware to handle data from nodes and to perform data processing and re-transmission towards the central unit. The flowchart of Figure 5(a) summarizes logic implemented by coordinator node; for receiving data from sensor nodes, it has to generate the Wi-Fi network in server modality, implemented in the block named Access Point by the method setupAccessPoint(). Hence, the NodeMCU module is set in reception modality by the method named handle_feed() corresponding to the Receiving data block. Inside the handle_feed method, the coordinator node receives data sent by $\mathrm{n}$-th node by calling the $\arg s($ ) method of the server object; subsequently, the data 
received from different sensor nodes are arranged within a bi-dimensional string array named DatiNodiSensore [Data][ID]; specifically, each column collects data related to i-th sensor node, whereas each row collects data related to a certain physical quantity acquired by cluster's WSN nodes. For filling the array, the handle feed() method employs a series of nested "if" conditional instructions, indexed by sensor node identifier (ID), as shown in Figure 5(b). Operatively, the coordinator node receives incoming data from sensor nodes for a fixed time interval $(30 \mathrm{~min})$; afterwards, it exits from the listening modality, extracts data from DatiNodoSensore [][] array, disables the access point modality and enables the Station Mode one for transmitting sensors data to the fertigator's control unit.

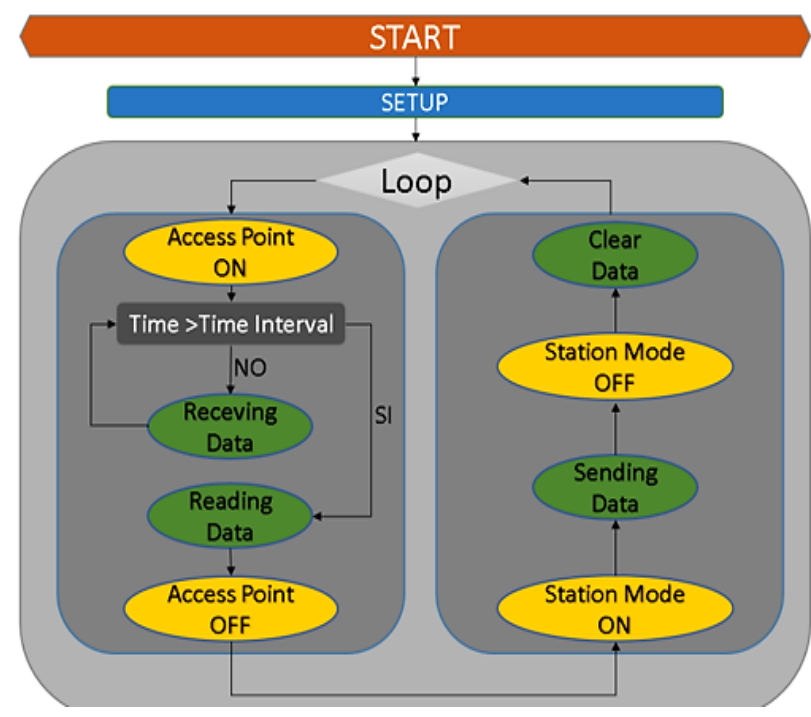

(a)

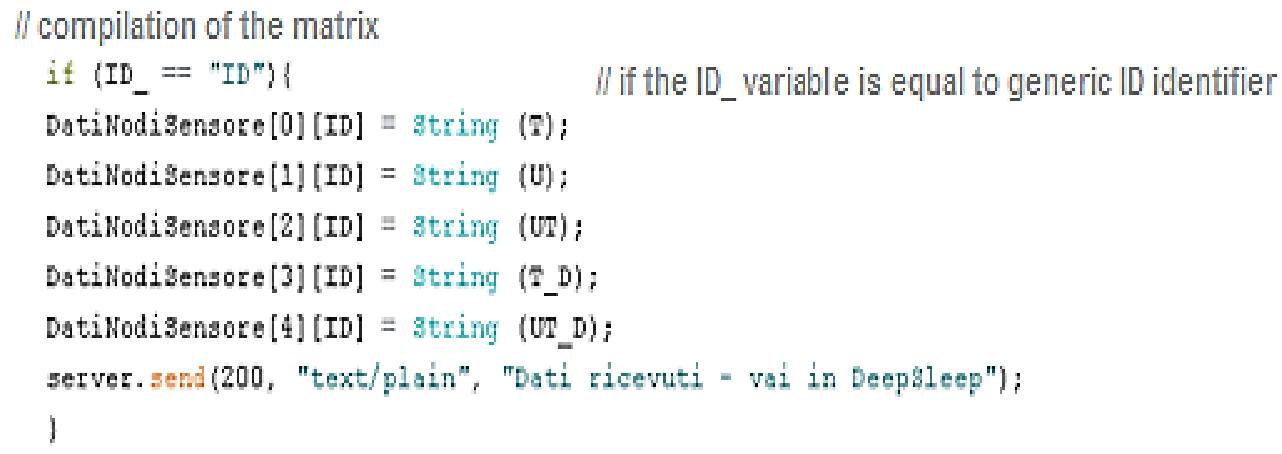

(b)

Figure 5. (a) Flowchart related to implemented logic by coordinator node, (b) Firmware section related to the array compilation with data from sensor nodes by a series of nested "if" conditional instructions

Afterwards, the client modality of coordinator node is disabled and it is brought in access point modality for restarting the measurement cycle above described. Just as an example of the characterization activity carried out in the research work, in Figure 6 is shown the experimental setup employed for measuring current consumptions of sensor and coordinator nodes, in different operating modes when powered by super-capacitor recharged by means of the solar harvesting system [25-27]. By using Hantek DSO5072P oscilloscope and placing a $2.2 \Omega$ sensing resistor in series with the power supply line of NodeMCU board, the absorbed current values during the different operation modes are measured. Also by analyzing acquired oscilloscope traces, the time duration of different node's operation phases is determined, thus allowing to calculate the energy consumption [28]. Afterwards, the WSN was tested on-field during the performed measurement campaigns, verifying the correctness of acquired data and their transmission between different types of nodes and to the central unit. 


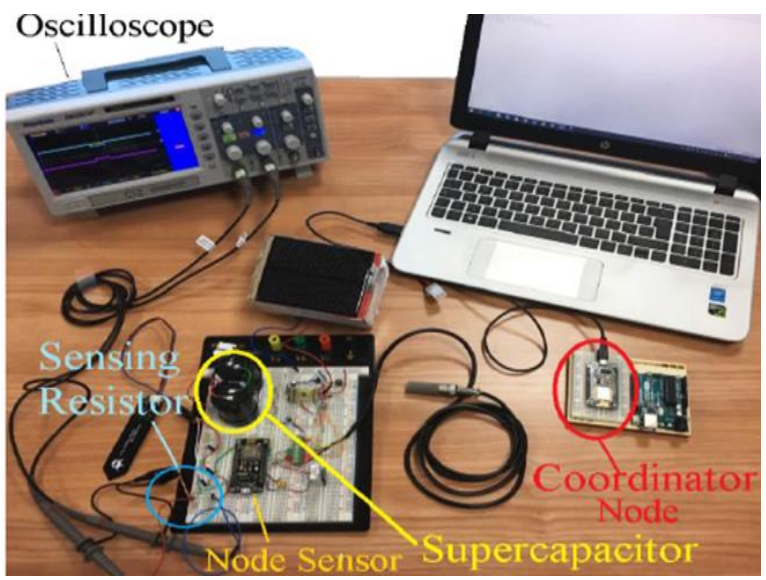

Figure 6. Experimental setup for determining power consumption of sensor node in different operation modalities (coordinator node searching, data detecting and transmission, deep-sleep state)

\section{RESULTS AND DISCUSSION}

\subsection{Development of the software platform and description of app's functionalities for the farmer}

The composition of fertilizing solutions is set on the base of agronomic models related to cultivated crops [11]. Each model has as inputs the weather information given by weather service and, mostly, the data directly detected on-field. The cloud software platform uses data for determining the correct nutriment and water requirements of plants related to the considered land's section, as function of crop typology and growth phase. This elaboration is carried out according to dynamic agronomic database the same for all fertigation systems; in addition, by means of proper calculation tools, the agronomic parameters can be constantly amended, in relation with results obtained on the cultivated crops [29]. Finally, a historical memory related to all operations performed on a particular land section or crop typology is available, for improving farmer's control over growth processes and at the same time to allow customers or wholesalers to monitor products quality. Figure 7 shows the main components of farming management system, with highlighted the data exchanges between different sections.

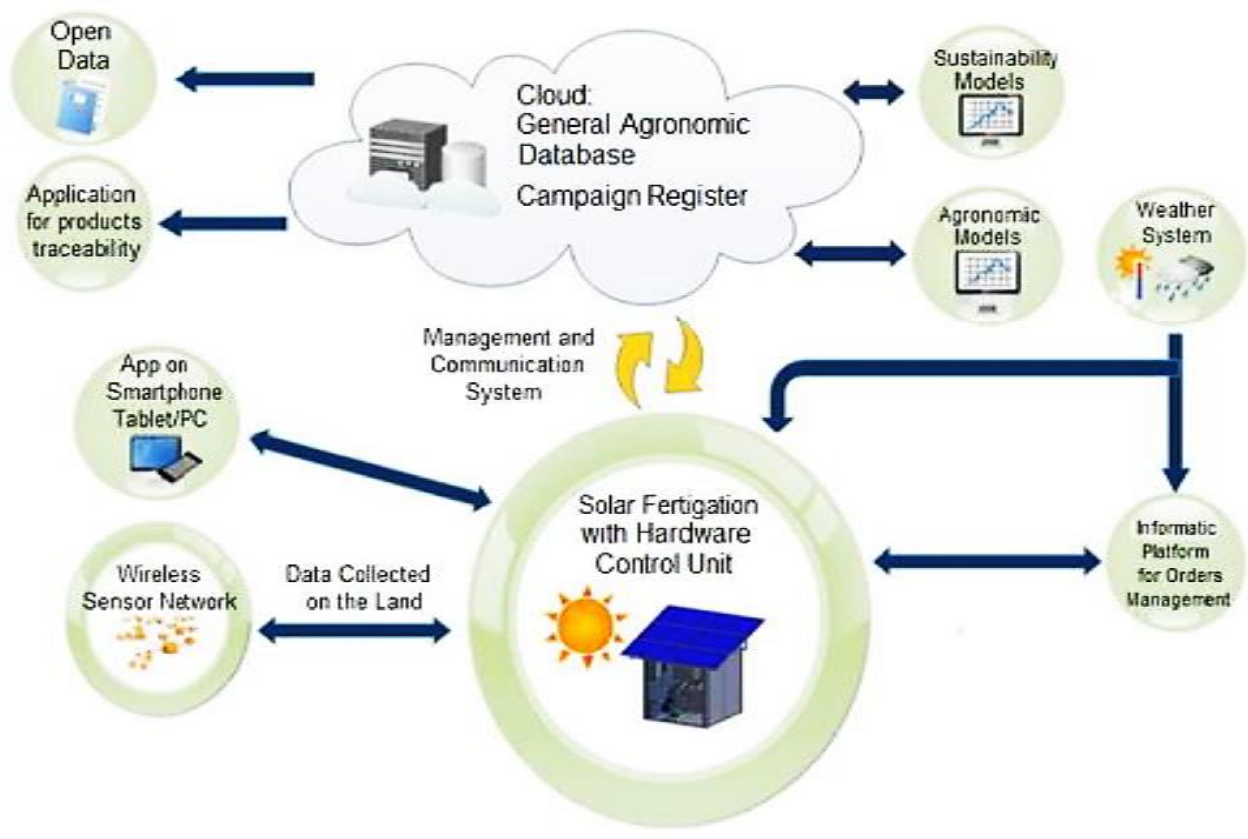

Figure 7. Fertigation system's block diagram with different sections and data exchanges between them; data related to crops' parameters and growth status are shared with cloud general agronomic database 
The developed software platform, containing the general agronomic data-base derived from the state of the art agronomic models, determines the parameters and threshold values employed by the fertigation system for agricultural processes. Moreover, the platform allows to remotely interact with the system and to control the crops' historical register of the different carried out operations. The software platform provides, in its architecture, different use modalities and user typologies with various access modes, services and functionalities. The farmer or agronomist can monitor or update the general agronomic data-base, view a summary of performed operations as well as command a specific treatment; the customers can view only information related to the carried out treatments and to products traceability [9]. The agronomic data, useful for crops cultivation, are contained both in user's on-cloud folder and local database that contains also information related to nutritional needs of each cultivated crop depending on the seasonal period, growth phase and specific environmental/geographical/meteorological conditions [29, 30].

The operation check of fertigation system is carried out by the farmer through the smartphone app directly on the land or by checking the local database parameters on the PC controlling the entire system; moreover, the farmer can update the database on the base of the on-site observations related to crops' phenological development. In addition, the agronomist can classify a land portion by assigning a QR-code, integrate the information on crops for increasing the customers' satisfaction as well as request the execution of a specific treatment on a land's portion for a given crop. For greater clarity and in order to highlight the functionalities and great utility of the developed smartphone application for the authorized users (farmers or customers), some real screenshots of it are shown and commented below. In Figure 8(a) a screenshot of view section of the smartphone application for the farmer (user M1) is shown; from this screen, the farmer can discern in visual way the sectors under irrigation (green) from those not irrigated (red). Clicking on "Status" button, he can monitor the instantaneous parameters of the considered sector; by means of the " $M$ " button, the user can manually command the irrigation of the considered sector regardless the information obtained by the agronomic model. Lastly, the farmer, by means of QR-code recognition functionality, can monitor in a rapid way the soil and air parameters and data history of the recognized sector, as shown in Figure 8(b). In Figure 8(c) it is reported the data history section related to sector 1, with the chronology of the WSN detected data and treatments carried out on the considered sector; to such section both the farmer and customer user can access from their account, instead only the farmer can access to the "settings" section for changing the parameters of fertigation phases respect to those defined by the agronomic model, shown in Figure 8(d) [31-34].

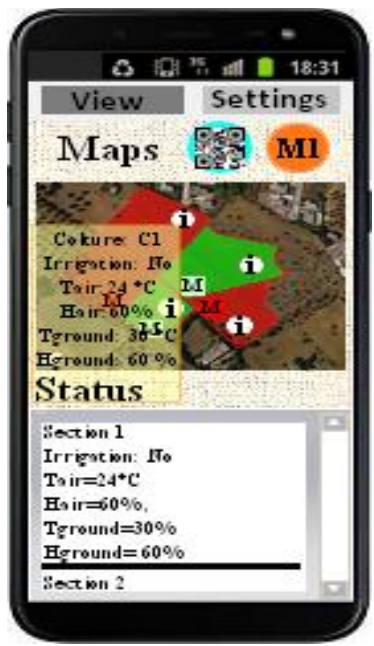

(a)

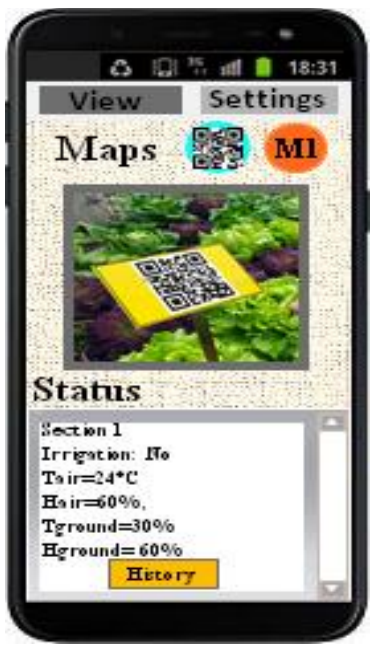

(b)

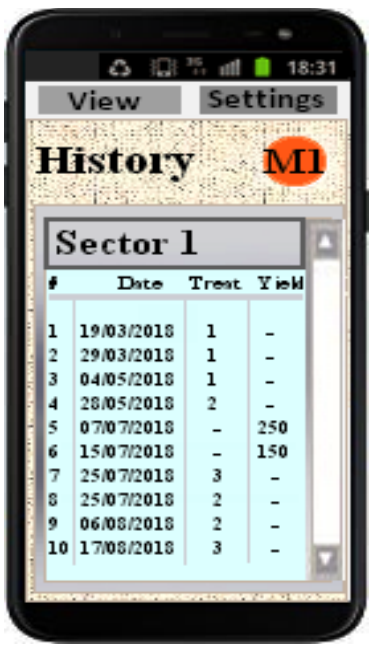

(c)

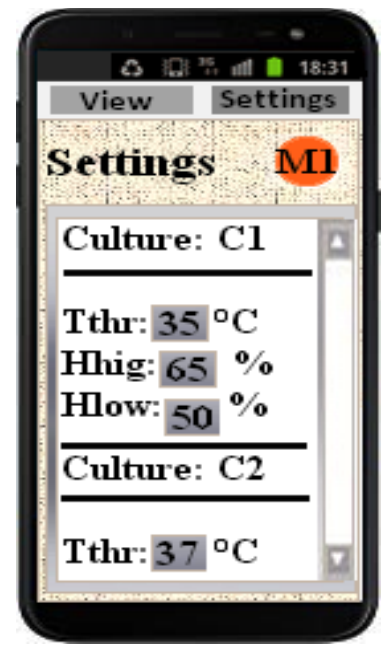

(d)

Figure 8. (a) Screenshots of realized application: view section where the farmer (user M1) has a complete overview of the cultivated crops, (b) QR code functionality used by the farmer to recognize on-field a specific crop or land's portion, (c) Data history section where the farmer or customer can monitor the crops' parameters (WSN data) and the performed fertigation treatments, (d) View of settings section where the farmer can change the threshold values of the fertigation system for a specific crop

The developed farming facility implements low cost technical solutions in each of its sections respect to other competitor systems. Obviously, the costs of the fertigation system and WSN depend on 
managed land size; for one hectare land, a cost of about $2800 €$ is needed for the hydraulic, mechanical and power sections of the fertigation system, whereas a cost of $35 €$ for each sensor node, lower than similar sensors-based devices (e.g. the Libelium waspmote kit). Supposing ten sectors for each hectare and one node per sector, the WSN cost is about $450 €$ including also the central unit and related electric actuation devices. Finally, in order to verify the correct functioning of the developed IoT-oriented farm management facility constituted by the sensor nodes installed in the cultivated ground and by the cloud software platform, different measurement campaigns were carried out actually on cultivated lands in different regions of southern Italy and the obtained results certify the correct functioning of the hardware and software sections. The smartphone screenshots, related to the developed software app and already described above, were actually captured during one of these measurement campaigns carried out on a one hectare land with reported the performed farming treatments and the cultivated crops' parameters.

\section{CONCLUSION}

Solar-powered high energy autonomy WSN supporting realized farming management system has been detailed; a tree topology was chosen to guarantee high robustness and flexibility. Low cost sensor nodes based on NodeMCU module and commercial sensors were used, power supplied by solar harvesting solution, for detecting environmental, soil and crops parameters and sending them by Wi-Fi technology to the control unit to be processed by comparison with threshold values (specific for each culture), in order to control the agricultural processes such as fertigation cycles thus optimizing fertilizers amount and typology. Based on results provided by the agronomic models combined with detected data by sensors and those provided by the weather service, in other words by integration of traditional cropping systems with the actual low-cost ICT technologies, a considerable reduction of fertilizers and water resources is ensured, so allowing a low environmental impact from crops cultivation. Developed IoT-oriented on-cloud platform allows automatic storing of detailed information related to crops and soil parameters as well as fertigation treatments carried out on the cultivated crops during the different growth phases, to be viewed by defined users. Also each plot of land is geo-localized, so that the system can take into account geographical features and soil parameters of the cultivation site. The developed platform allowss to common users or possible buyers to obtain traceability information relative to agri-food products throughout the supply chain, so providing to them an added value and thus a greater economic return for the farmer; in this way, customers can ascertain the production process of considered agri-food and their quality standards, even before placing a purchase order. Finally, designed farming facility was really tested on field for checking right performance of hardware and software sections together with proper operation of the control applications available on smartphone for the enabled users.

\section{REFERENCES}

[1] N. I. Tcherny shev, O. E. Sy soev, D. Solovev, and E. P. Kisely ov, "Basic robotecnical platform for implementation of accurate farming technologies," Bulletin of Electrical Engineering and Informatics, vol. 7, no. 4, pp. 522-528, 2018.

[2] A. Kamilaris, A. Kartakoullis, and F. X. Prenafeta-Boldú, "A review on the practice of big data analysis in agriculture," Computers and Electronics in Agriculture, vol. 143, pp. 23-37, 2017.

[3] A. Priya and T. Sasilatha, "Wireless network for strategic boundary supervision system," Bulletin of Electrical Engineering and Informatics, vol. 6, no. 4, pp.367-370, 2017.

[4] P. Visconti, P. Primiceri, and C. Orlando, "Solar powered wireless monitoring system of environmental conditions for early flood prediction or optimized irrigation in agriculture," ARPN Journal of Engineering and Applied Sciences, vol. 11, no. 7, pp. 4623-4632, 2016.

[5] P. Visconti, p. primiceri, R. Ferri, M. Pucciarelli, and E. Venere, "An overview on state-of-art energy harvesting techniques and related choice criteria: A WSN node for goods transport and storage powered by a smart solar-based EH system," International Journal of Renewable Energy Research (IJRER), vol. 7, no. 3, pp. 1281-1295, 2017.

[6] P. Visconti, R. de Fazio, P. Costantini, S. Miccoli, and D. Cafagna, "Arduino-based solution for in-car-abandoned infants' controlling remotely managed by smartphone application," Journal of Communications Software and Systems, vol. 15, no. 2, pp. 1-12, 2019.

[7] M. J. Alam, Md. A. Awal, and Md. N. Mustafa, "Crops diseases detection and solution system," International Journal of Electrical and Computer Engineering (IJECE), vol. 9, no. 3, pp. 2112-2120, June 2019.

[8] N. Zainal, N. Mohamood, M. F. Norman, and D. Sanmutham, "Design and implementation of smart farming system for fig using connected-agronomics," International Journal of Electrical and Computer Engineering (IJECE), vol. 9, no. 6, pp. 5653-5662, 2019.

[9] F. Kamaruddin et al., "IoT-based intelligent irrigation management and monitoring system using arduino," TELKOMNIKA Telecommunication Computing Electronics and Control, vol. 17, no. 5, pp. 2378-2388, October 2019.

[10] S. Navulur, A. S. C. S. Sastry, and M. N. G. Prasad, "Agricultural management through wireless sensors and Internet of Things," International Journal of Electrical and Computer Engineering), vol. 7, no. 6, pp. 3492-3499, 2017. 
[11] K. Phoksawat and M. Mahmuddin, "Knowledge and integrated data management model for personalized intercropping in rubber plantation," International Journal of Electrical and Computer Engineering (IJECE), vol. 9, no. 6 , pp. 5502-5511, 2019.

[12] V. Rossi, T. Caffi, S. Legler, E. Carotenuto, and G. Bigot, "Large-scale application of a web-based decision support system for sustainable viticulture," IOBC/WPRS Bulletin, vol. 105, pp. 129-136. 2014.

[13] E. Essien, K. A. Dzisi, and A. Addo, "Decision support system for designing sustainable multi-stakeholder networks of grain storage facilities in developing countries," Computers and Electronics in Agriculture, vol. 147, pp. 126-130, 2018.

[14] A. Hafezalkotob, A. Hami-Dindar, N. Rabie, and A. Hafezalkotob, "A decision support system for agricultural machines and equipment selection: A case study on olive harvester machines," Computers and Electronics in Agriculture, vol. 148, pp. 207-216, 2018.

[15] R. Lokers, R. Knapen, S. Janssen, Y. van Randen, and J. Jansen, "Analysis of Big Data technologies for use in agro-environmental science," Environmental Modelling \& Software, vol. 84, pp. 494-504, 2016.

[16] K. Foughali, k. Fathallah, and A. Frihida, "Using Cloud IoT for disease prevention in precision agriculture," Procedia Computer Science, vol. 130, pp. 575-582, 2018.

[17] J. Polo, G. Hornero, C. Duijneveld, A. Garcia, and O. Casas, "Design of a low-cost wireless sensor network with UAV mobile node for agricultural applications," Computers and Electronics in Agriculture, vol. 119, pp. 19-32, 2015.

[18] J. M. Talavera et al., "Review of IoT applications in agro-industrial and environmental fields," Computers and Electronics in Agriculture, vol. 142, pp. 283-297, 2017.

[19] A. Kamilaris and F. X. Prenafeta-Boldú, "Deep learning in agriculture: A survey," Computers and Electronics in Agriculture, vol. 147, pp. 70-90, 2018.

[20] A. A. Jaber, F. Khalil, I. Al-Mousawi, and H. S. Jasem, "Internet of things based industrial environment monitoring and control: A design approach," International Journal of Electrical and Computer Engineering, vol. 9, no. 6, pp. 4657-4667, 2019.

[21] S. I. Abdullahi, M. H. Habaebi, and N. A. Malik, "Capacitive electrode sensor implanted on a printed circuit board designed for continuous water level measurement," Bulletin of Electrical Engineering and Informatics, vol. 8, no. 2, pp. 450-459, 2019.

[22] P. Visconti, C. Orlando, and P. Primiceri, "Solar powered WSN for monitoring environment and soil parameters by specific app for mobile devices usable for early flood prediction or water savings," IEEE 16th International Conference on Environment and Electrical Engineering (EEEIC), Florence, pp. 1-6, 2016.

[23] G. Samara and M. Aljaidi, "Efficient energy, cost reduction, and QoS based routing protocol for wireless sensor networks," International Journal of Electrical and Computer Engineering (IJECE), vol. 9, no. 1, pp. 496-504, 2019.

[24] F. Muzafarov and A. Eshmuradov, "Wireless sensor network based monitoring system for precision agriculture in Uzbekistan," TELKOMNIKA Telecommunication Computing Electronics and Control, vol. 17, no. 3, pp. 1071-1080, 2019.

[25] P.Visconti, R. Ria, and G. Cavalera, "Development of smart PIC-based electronic equipment for managing and monitoring energy production of photovoltaic plan with wireless transmission unit," ARPN Journal of Engineering and Applied Sciences, vol. 10, no. 20, pp.9434-9441, 2015.

[26] P. Visconti, B. Sbarro, and P. Primiceri, "Design and testing of electronic control system based on STM X-Nucleo board for detection and wireless transmission of sensors data applied to a single-seat Formula SAE car," International Journal of Electronics and Telecommunications, vol. 65, no. 4, pp. 671-678, 2019.

[27] N. Rawat, P. Thakur, and U. Jadli, "Solar PV parameter estimation using multi-objective optimisation," Bulletin of Electrical Engineering and Informatics, vol. 8, no. 4, pp. 1198-1205, 2019.

[28] P. Visconti, R. Ferri, M. Pucciarelli, and E. Venere, "Development and characterization of a solar-based energy harvesting and power management system for a WSN node applied to optimized goods transport and storage," International Journal on Smart Sensing and Intelligent Systems, vol. 9, no. 4, pp. 1637-1667, 2016.

[29] M. Khairie et al., "Advancement of a smart fibrous capillary irrigation management system with an Internet of Things integration," Bulletin of Electrical Engineering and Informatics, vol. 8, no. 4, pp. 1402-1410, 2019.

[30] S. I. Abdullahi, M. H. Habaebi, and N. Abd Malik., "Intelligent flood disaster warning on the fly: developing IoT-based management platform and using 2-class neural network to predict flood status," Bulletin of Electrical Engineering and Informatics, vol. 8, no. 2, pp. 706-717, 2019.

[31] C. C. Baseca, S. Sendra, J. Lloret and J. Tomas, "A Smart Decision System for Digital Farming," Agronomy, vol. 9, no. 216, pp. 1-19, 2019.

[32] M. Bacco, P. Barsocchi, E. Ferro, A. Gotta, M. Ruggeri, "The Digitisation of Agriculture: a Survey of Research Activities on Smart Farming," Array, vol. 3-4, p. 100009, 2019.

[33] Z. Zhai, J. F. Martínez, V. Beltran, N. L. Martínez, "Decision support systems for agriculture 4.0: Survey and challenges," Computers and Electronics in Agriculture, vol. 170, p.105256, 2020.

[34] T. Adiono, S. F. Anindya, S. Fuada, M. Y. Fathany, "Curtain Control Systems Development on Mesh Wireless Network of the Smart Home," Bulletin of Electrical Engineering and Informatics, vol. 7, no. 4, pp. 615-625, 2018. 